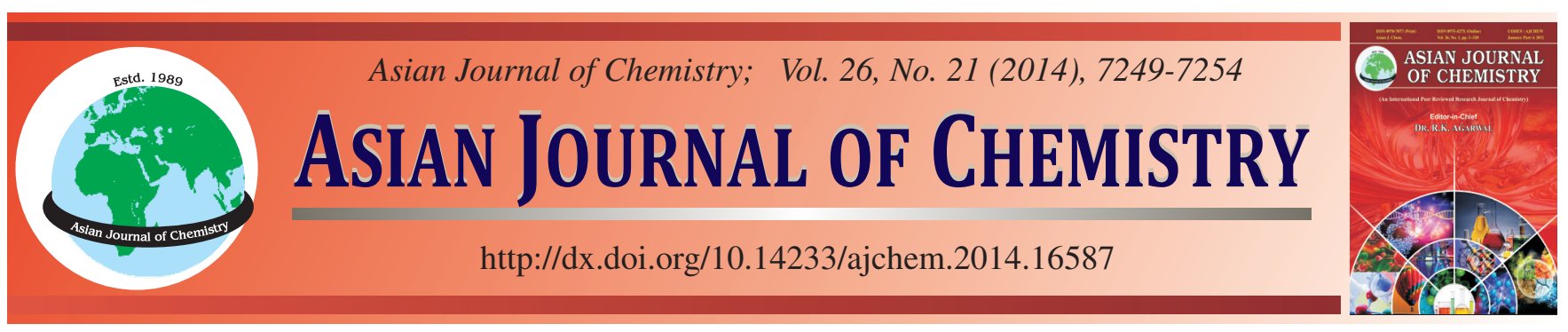

\title{
Adsorption Mechanisms of Quercetin, Catechin and Epicatechin on Quercetin Molecular Imprinted Polymer using Linear Solvation Energy Relationship
}

\author{
Y. JIN ${ }^{1}$, Y.D. CHENG ${ }^{1}$, Y.S. Song ${ }^{1}$, K.H. Row ${ }^{2}$, Y.S. JIN ${ }^{3}$, Y.H. XUAN ${ }^{4}$ and M.J. JIN ${ }^{5, *}$
}

${ }^{1}$ College of Food Science and Technology, Shanghai Ocean University, Shanghai 201-306, P.R. China

${ }^{2}$ Department of Chemical Engineering, Inha University, Incheon 402-751, Republic of Korea

${ }^{3}$ College of Bioscience and Biotechnology, Yangzhou University, Yangzhou 225-009, P.R. China

${ }^{4}$ Yangzhou University Library, Yangzhou University, Yangzhou 225-009, P.R. China

${ }^{5}$ Department of Forestry Science, Agricultural College of Yanbian University, Yanji 133-002, Jilin Province, P.R. China

*Corresponding author: Fax: +86 433 2435600, Tel: +86 433 2435556; E-mail: jinmingji@ybu.edu.cn; yzjin@ shou.edu.cn

\begin{abstract}
The fundamental chemical interactions governing the adsorption of three polyphenols such as quercetin, catechin and epicatechin on quercetin-molecular imprinted polymer using linear solvation energy relationship model were investigated. The quercetin-molecular imprinted polymer was prepared with quercetin as the template and methacrylic acid as the functional monomer. Acetonitrile and methanol were used as the porogen with ethylene glycol dimethacrylate (EGDMA) as the crosslinker and 2,2'-azobis (isobutyronitrile) (AIBN) as the initiator. The static method was performed on the manufactured quercetin-molecular imprinted polymer particles. The ability of the linear solvation energy relationship to account for the chemical interactions underlying solute adsorption was shown. A comparison of predicted and experimental adsorption concentrations suggests that linear solvation energy relationship formalism is able to reproduce adequately the experimental adsorption concentrations of the solutes studied in the different experimental conditions investigated. The constants of linear solvation energy relationship model were also predicted using Logarithmic and Polynomial equations. The Polynomial equation shows more good agreement than Logarithmic equation for predict the constants of linear solvation energy relationship model in solution of single compound or mixture compounds of quercetin, catechin and epicatechin. However, the predicted adsorption concentrations by the linear solvation energy relationship model have good agreement with experimental data in the employed experimental conditions.
\end{abstract}

Keywords: Adsorption, Quercetin, Catechin, Epicatechin, Molecular imprinted polymer, Linear solvation energy relationship.

\section{INTRODUCTION}

The technique of molecular imprinting consists of the selfassembly of a functional monomer and a template molecule in solution followed by co-polymerization of the functional monomer and an excess of an appropriate crosslinking monomer. After removal of small molecules, the resulting network polymer exhibits significantly higher affinity for the molecules used as the template than for similar molecules, including closely related isomers ${ }^{1-5}$. Normally, the molecular imprinted polymer (MIP) shows extraordinarily higher adsorption ability for template molecule than for the other compounds that were also assessed $d^{5-7}$.

Understanding the thermodynamics of equilibrium between a solution and a solid adsorbent is essential to assess the performance of a porous material in terms of molecular recognition. An adsorbent wet by a solution will adsorb selectively one or a few components of the solution. This selectivity depends on the composition of the liquid. A direct application of this phenomenon is the separation of samples in reversedphase liquid chromatography (RPLC) $)^{8}$. Retention prediction and selectivity optimization are very important in rapid method development in RPLC. However, retention in RPLC is a very complicated process that depends on many physical and chemical properties of the system, such as temperature, solute molecular properties, stationary phase characteristics and mobile phase composition. These years many practical retention models for RP-HPLC, such as linear solvation energy relationships (LSER), have been developed and widely used ${ }^{9,10}$.

Quantitative structure-activity relationship (QSAR) theory was developed in the form of a linear solvation energy relationship (LSER) by Kamlet et al. ${ }^{11}$, who used a multi-parameter approach to describe configurational properties in terms of a solute cavity in a solvent and the solvent-solute interactions. Since then, the theory has been adapted to other aspects of chemistry including reaction rates, toxicity, fluorescence 
lifetimes and others. Linear solvation energy relationship methods involve the application of solvent parameters in linear or multiple-linear regression formulations to express solvent effects for property and reactivity prediction. Properties of mixtures, such as chromatographic retentions, water-octanol partition coefficients and solubilities have been successfully predicted using LSER methods ${ }^{12,13}$.

The LSER equation used in this study is:

$$
\log \mathrm{Cs}=\mathrm{m}\left(\mathrm{V}_{\mathrm{x}} / 100\right)+\mathrm{s} \pi^{\mathrm{H}}+\mathrm{a} \Sigma \alpha^{\mathrm{H}}+\mathrm{b} \Sigma \beta^{\mathrm{H}}+\mathrm{c}
$$

where, $\mathrm{Cs}$ is the experimental adsorption concentration. The $\mathrm{V}_{\mathrm{x}}, \pi^{\mathrm{H}}, \Sigma \alpha^{\mathrm{H}}$ and $\Sigma \beta^{\mathrm{H}}$ terms are solute descriptors, where $\mathrm{V}_{\mathrm{x}}$ represents the solute's size/polarizability, $\pi^{\mathrm{H}}$ is the dipolarity/ polarizability, $\Sigma \alpha^{\mathrm{H}}$ is the hydrogen bond (HB) acidity and $\Sigma \beta^{\mathrm{H}}$ is the hydrogen bond basicity. The coefficients of these descriptors $\mathrm{m}, \mathrm{s}$, a and $\mathrm{b}$ reflect differences in the two bulk phases between which the solute is transferring and are obtained through a multi-parameter linear regression. The $\mathrm{c}$ term is simply the intercept of the regression and is comprised of constant contributions from the solutes and the chromatographic system. It is noted that since the parameters $\mathrm{V}_{\mathrm{x}}$ and $\pi^{\mathrm{H}}$ are blends of two different interactions, the coefficients of these parameters are also blends of the corresponding properties. Specifically, $\mathrm{m}$ is the difference in the cohesivity/dispersive ability of the two bulk phases and $\mathrm{s}$ is the difference in the ability of the two phases to interact through dipole-dipole and dipole-induced dipole interactions. Many reviews and examples of LSERs and their interpretations are available ${ }^{14}$.

In this study, the adsorption mechanisms of three polyphenols (quercetin, catechin and epicatechin) on quercetinmolecular imprinted polymer were investigated using linear solvation energy relationship.

\section{EXPERIMENTAL}

Quercetin, (+) catechin (+C), (-) epicatechin (EC) and methacrylic acid (MAA) were purchased from Sigma (St. Louis, MO, USA). Ethylene glycol dimethacrylate (EGDMA) was purchased from Fluka (Buchs, Switzerland). 2,2'-Azobis(isobutyronitrile) (AIBN) was produced by Junsei Chemical Co. Ltd. (Japan) and refined before use. Methanol, acetonitrile and trifluoroacetic acid were obtained from Pure Chemical Co., Ltd. (Ansan, Korea). Acetic acid (A. R.) was from Oriental Chemical Industries (Incheon, Korea). All the other solvents used in the experiment were of HPLC or analytical grade. Distilled water was filtered using a vacuum pump (Division of Millipore, Waters, USA) and a filter (HA-0.45, Division of Millipore, Waters, USA) before use. All the samples were filtered (MFS-25, 0.2 pm TF, Whatman, USA) before injection into the HPLC system.

Polymer preparations: To a $250 \mathrm{~mL}$ two-neck glass flask were added $5 \mathrm{mmol}$ of the monomer methacrylic acid (MAA), $30 \mathrm{mmol}$ of the crosslinker (EGDMA), $0.12 \mathrm{~g}$ of the initiator (AIBN), $9 \mathrm{~mL}$ of acetonitrile, $5 \mathrm{~mL}$ methanol of the porogen and $1 \mathrm{mmol}$ of the template (quercetin). The reaction mixture was subjected to supersonication for $10 \mathrm{~min}$, sparged with helium for $10 \mathrm{~min}$ for the removal of oxygen and then vacuumed for $10 \mathrm{~min}$ and sealed under vacuum. Polymerization was performed in a water bath that was held at $60^{\circ} \mathrm{C}$ for $24 \mathrm{~h}$. After the polymerization, the bulk polymer was removed from the reaction flask and put in an oven for drying. The dried polymer was ground into particles and passed through a $32 \mu \mathrm{m}$ sieve; small particles were removed by repeated sedimentations with water. After these procedures, particles of 25-32 $\mu \mathrm{m}$ in size were collected.

HPLC analysis: The chromatography system comprised of a Waters 600s Multi solvent Delivery System and a Waters 616 liquid chromatography (Waters Associates, Milford, MA, USA), a Rheodyne injector ( $20 \mu \mathrm{L}$ sample loop) and a variable wavelength 2487 UV dual channel detector. Data processing was carried out with Millenium 3.2 using a HP Vectra 500 PC. Under the chromatographic condition, the flow rate was 0.5 $\mathrm{mL} / \mathrm{min}$, the injection volume was $5 \mu \mathrm{L}$ and the UV wavelength was $270 \mathrm{~nm}$. A $\mathrm{C}_{18}$ column ( $5 \mu \mathrm{m}$ particles, $10 \mathrm{~nm}$ pore sizes, $4.6 \times 250 \mathrm{~mm}$ ) from RS Tech. Corporation (Daejeon, Korea), where $\mathrm{V}($ water $) / \mathrm{V}$ (acetonitrile) $/ \mathrm{V}(\mathrm{TFA})=50 / 50 / 0.5$ was the mobile phase, was used to determine the free concentration of the compound via the static method.

Static methods: The static method was performed on the manufactured polymer particles. Ten aliquots of $30 \mathrm{mg}$ of the quercetin-imprinted polymer were placed into $10 \mathrm{~mL}$ flasks, respectively, to which $3 \mathrm{~mL}$ of quercetin, catechin or epicatechin solution with a concentration of 0.15 to $2 \mathrm{mmol} / \mathrm{L}$ was added and also a mixture solution of quercetin, catechin and epicatechin with different concentrations was added. The mixture was left at room temperature for $72 \mathrm{~h}$ and then the supernatant was collected and filtered $(0.2 \mu \mathrm{m})$. The concentrations of free quercetin, catechin and epicatechin in the solution were determined on $\mathrm{C}_{18}$ column at room temperature. Absorbed quercetin, catechin and epicatechin concentrations on the molecular-imprinted polymer were calculated by subtracting the concentrations of free quercetin, catechin and epicatechin from the initial concentrations of these compounds.

Linear solvation energy relationship estimations: Adsorption concentrations were determined for the three polyphenols such as quercetin, catechin and epicatechin used in this study and the system constants were calculated by multiple linear regressions using Origin Pro 8.0 software (Microcal Software Inc., MA, USA). The differences in LSER coefficients indicate the variations in the types of interactions between molecular imprinted polymer and solutes.

\section{RESULTS AND DISCUSSION}

After mixing the target compound solution and the quercetin-molecular imprinted polymer particles for $72 \mathrm{~h}$, the adsorption equilibrium could be obtained between the two phases. The free concentration of single or mixture compounds of quercetin, catechin and epicatechin in the liquid phase were quantitatively determined by HPLC, respectively. The chromatogram of the mixture compounds of quercetin, catechin and epicatechin on quercetin-molecular imprinted polymer by analytical HPLC was shown in Fig. 1. The chemical structures of these three compounds were similar (Fig. 1) and the catechin and epicatechin were separated from green tea by HPLC, usually ${ }^{15-17}$. The calibration curve (concentration (Y) vs. peak area $(\mathrm{X})$ ) was constructed in the range of 0.05 to $2.00 \mathrm{mmol} / \mathrm{L}$. The regression coefficients of the calibration equations were all above 0.99 (Table-1). 


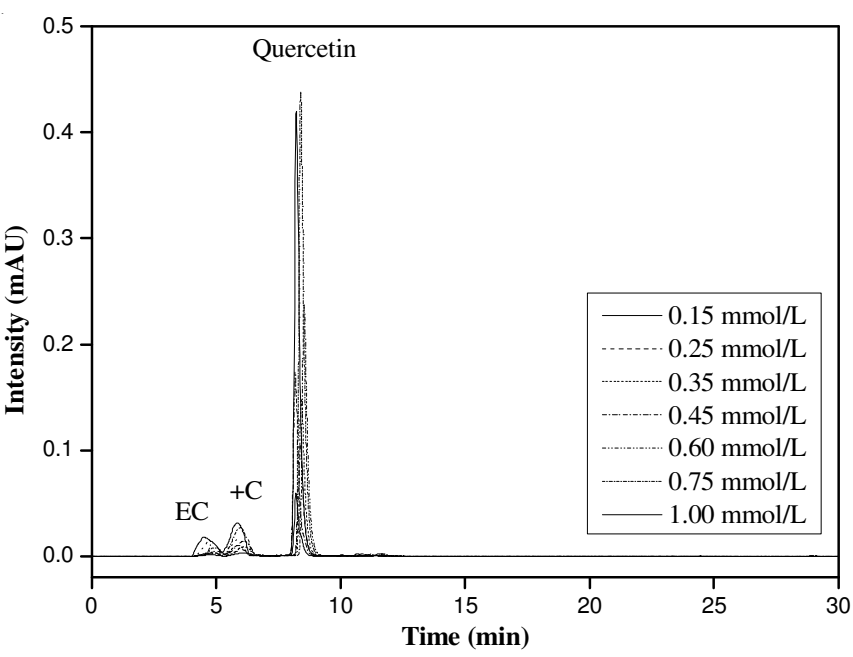

Fig. 1. Chromatogram of the mixture compounds of quercetin, catechin and epicatechin on quercetin-MIP by analytical HPLC

\begin{tabular}{ccc}
\multicolumn{3}{c}{ TABLE-1 } \\
CALIBRATION EQUATIONS OF QUERCETIN, \\
CATECHIN AND EPICATECHIN \\
\hline Compound & Equation & $\mathrm{R}^{2}$ \\
\hline Quercetin & $\mathrm{y}=1 \times 10^{-7} \mathrm{x}+0.020$ & 0.9970 \\
Catechin & $\mathrm{y}=6 \times 10^{-7} \mathrm{x}+0.016$ & 0.9990 \\
Epicatechin & $\mathrm{y}=6 \times 10^{-7} \mathrm{x}+0.038$ & 0.9950 \\
\hline $\mathrm{x}:$ peak area $\left(\mathrm{mAU} \mathrm{USec}^{\mathrm{S}}\right), \mathrm{y}:$ concentration $(\mathrm{mmol} / \mathrm{L})$ &
\end{tabular}

The experimental results of the adsorption concentrations of single and mixture compounds on the quercetin-molecular imprinted polymer were shown in Tables 2 and 3, respectively. The adsorption concentrations of quercetin, catechin and epicatechin on the molecular imprinted polymer increase with the increased concentrations of the solutions. The adsorption concentration of quercetin on the molecular imprinted polymer is higher than the adsorption concentrations of catechin and epicatechin on the molecular imprinted polymer. The imprinted polymer surface is often regarded as heterogeneous and there are two kinds of binding sites on the imprinted polymer surface, one is selective or has high affinity with high binding energy and the other is nonselective or has low affinity with low binding energy ${ }^{18}$. In the low concentration range, the adsorption on selective binding sites is stronger than that on nonselective binding sites ${ }^{18}$. The adsorption concentrations of catechin and epicatechin on the molecular imprinted polymer were similar when a single compound was adsorbed on quercetin-molecular imprinted polymer. When the mixture compounds were adsorbed on quercetin-molecular imprinted polymer, the adsorption concentrations of catechin and epicatechin on the molecular imprinted polymer were different. Comparing the adsorption of the single compound and that of it in the mixture compounds, the adsorption concentrations of catechin on the molecular imprinted polymer in the adsorption and competitive adsorption were similar. However, the adsorption concentrations of quercetin and epicatechin on the molecular imprinted polymer for their single compound adsorption were smaller than the adsorption concentrations of quercetin and epicatechin on the molecular imprinted polymer for the mixture compounds adsorption, respectively. This indicates that the mixture compounds were adsorbed competitively on the specific
TABLE-2

ADSORPTION AMOUNTS OF SINGLE COMPOUNDS

OF QUERCETIN, CATECHIN AND EPICATECHIN ON QUERCETIN-MIP

\begin{tabular}{cccc}
\hline \multirow{2}{*}{$\mathrm{Cm}(\mathrm{mmol} / \mathrm{L})$} & \multicolumn{3}{c}{ Cs $(\mathrm{mmol} / \mathrm{L})$} \\
\cline { 2 - 4 } & Quercetin & Catechin & Epicatechin \\
\hline 0.15 & 0.0792 & 0.0771 & 0.0763 \\
0.25 & 0.1502 & 0.1289 & 0.1316 \\
0.35 & 0.2300 & 0.1821 & 0.1886 \\
0.45 & 0.3157 & 0.2481 & 0.2397 \\
0.60 & 0.4398 & 0.3218 & 0.3228 \\
0.75 & 0.5852 & 0.4055 & 0.4068 \\
1.00 & 0.7828 & 0.5359 & 0.5328 \\
1.25 & 0.9682 & 0.6737 & 0.6643 \\
1.50 & 1.1147 & 0.8119 & 0.8060 \\
2.00 & 1.4010 & 1.0723 & 1.0712 \\
\hline
\end{tabular}

TABLE-3

ADSORPTION AMOUNTS OF MIXTURE COMPOUNDS OF QUERCETIN, CATECHIN AND EPICATECHIN ON QUERCETIN-MIP

\begin{tabular}{cccc}
\hline \multirow{2}{*}{$\mathrm{Cm}(\mathrm{mmol} / \mathrm{L})$} & \multicolumn{3}{c}{ Cs $(\mathrm{mmol} / \mathrm{L})$} \\
\cline { 2 - 4 } & Quercetin & Catechin & Epicatechin \\
\hline 0.15 & 0.0933 & 0.0383 & 0.0511 \\
0.25 & 0.1623 & 0.0987 & 0.1019 \\
0.35 & 0.2239 & 0.1566 & 0.1385 \\
0.45 & 0.2971 & 0.2101 & 0.1811 \\
0.60 & 0.3903 & 0.2990 & 0.2385 \\
0.75 & 0.4835 & 0.3969 & 0.3120 \\
1.00 & 0.6608 & 0.5543 & 0.4316 \\
\hline
\end{tabular}

binding sites of quercetin-molecular imprinted polymer. The effect of competitive adsorption was investigated with the parameters of the adsorption isotherm model for a single compound ${ }^{5}$.

Sorbent-analyte interactions fall into three categories i.e., non-polar, polar and ionic. Non-polar sorbents are generally selected for extracting triazines from water. By contrast, degradation products, which contain polar functional groups such as hydroxyl, carbonyls, amines and sulfhydryls, need polar sorbents. Polar sorbents exhibit a strong tendency to form hydrogen bonds. Analytes that are capable of forming cations include amines; analytes with the potential to form anions, including carboxylic, sulfonic acids and phosphates. In comparison with traditional stationary phase extraction materials, a unique property of molecular imprinted polymer is their lockkey relationship with the target molecule and hence their selectivity can be predetermined ${ }^{19}$. Although the effect of particle size on the performance of separation is important, it was not considered here and will be left for further work. Generally, molecular imprinted polymer exhibits better molecular recognition in the solvent used as porogen during polymerization. It was revealed that selective binding of the template to the molecular imprinted polymer is enhanced in conditions similar to those occurring during the molecular self-assembly in the polymerization mixture ${ }^{4}$.

The adsorption behaviors of the quercrtin, catechin and epicatechin in each adsorption concentrations were examined and compared using the solvation parameter LSER model, i.e., model described in eqn. 1 . The test solutes and their descriptors used in this study are given in Table- $4^{20}$. The coefficients for the LSER equations obtained for concentrations of single 
compound were listed in Table-5 and Fig. 2. In all the concentration investigated all of the values of a and $\mathrm{m}$ were zero whether solutions of single or mixture compounds (Table- 6 and Fig. 3). The coefficient a is an important factor in the solvatochromic model in the two systems studied ${ }^{14}$. This coefficient represents the difference in the hydrogen bond accepting basicity of the solutes and quercetin-molecular imprinted polymer. All of the values of a of three compounds on molecular imprinted polymer can not calculated. Because all of the hydrogen bond (HB) acidities of these three compounds on quercetin-molecular imprinted polymer were zero. Also, the values of $\mathrm{m}$ can not calculated and all of the solute's size/polarizability of these three compounds such as quercetin, catechin and epicatechin on molecular imprinted polymer were zero. In all the concentration investigated all of the values of $b$

\begin{tabular}{|c|c|c|c|c|}
\hline \multicolumn{5}{|c|}{$\begin{array}{c}\text { TABLE-4 } \\
\text { TEST QUERCETIN, CATECHIN, EPICATECHIN AND THEIR } \\
\text { DESCRIPTORS FOR THE SALVATION PARAMETER MODEL }{ }^{20}\end{array}$} \\
\hline \multirow{2}{*}{ Compounds } & \multicolumn{4}{|c|}{ Descriptors } \\
\hline & $\mathrm{V}_{\mathrm{X}} / 100$ & $\pi^{\mathrm{H}}$ & $\alpha^{\mathrm{H}}$ & $\beta^{\mathrm{H}}$ \\
\hline Quercetin & 1.96 & 2.44 & 1.94 & 1.32 \\
\hline Catechin & 1.99 & 2.45 & 2.30 & 1.81 \\
\hline Epicatechin & 1.99 & 2.73 & 2.30 & 1.84 \\
\hline
\end{tabular}
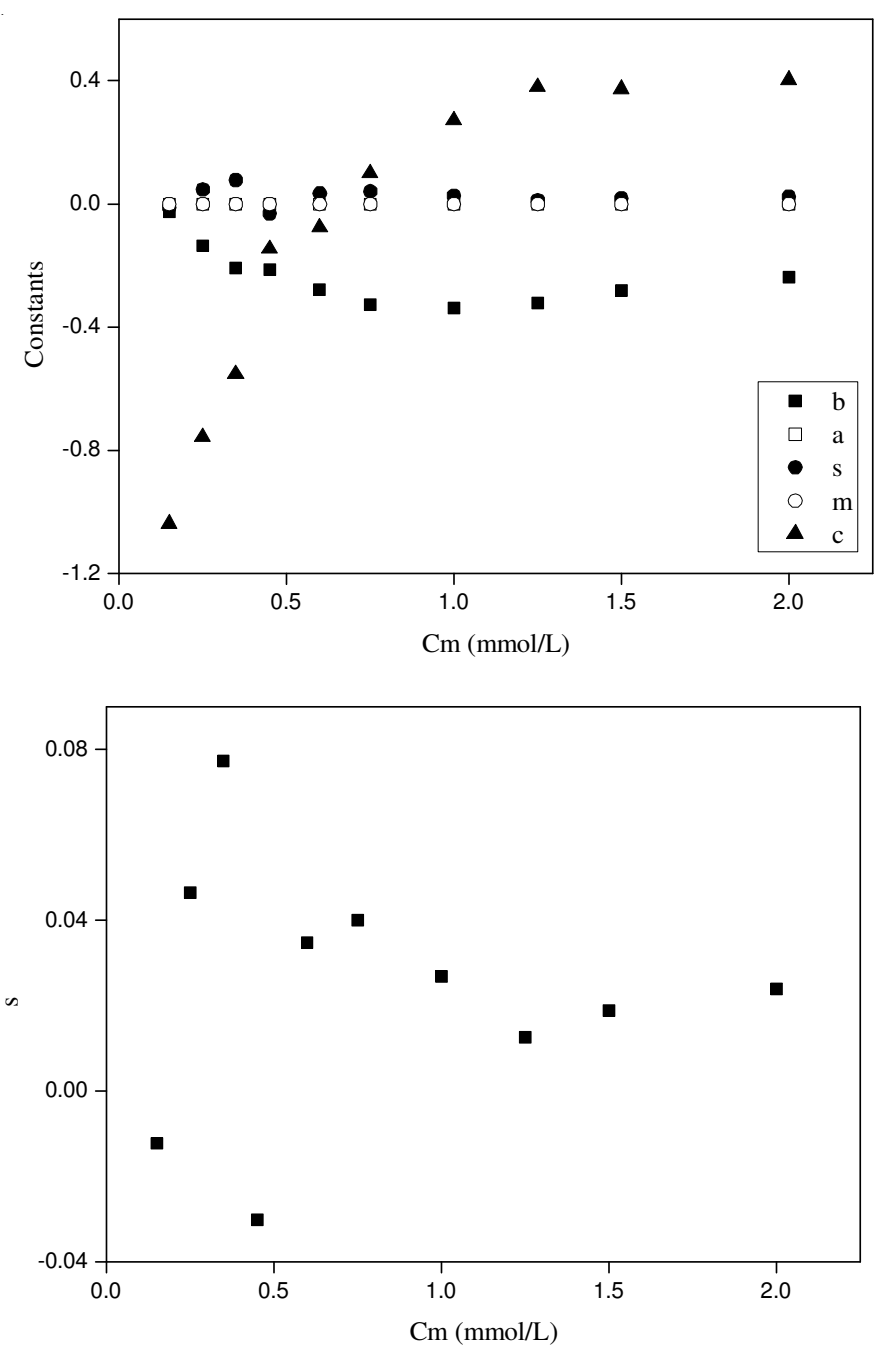

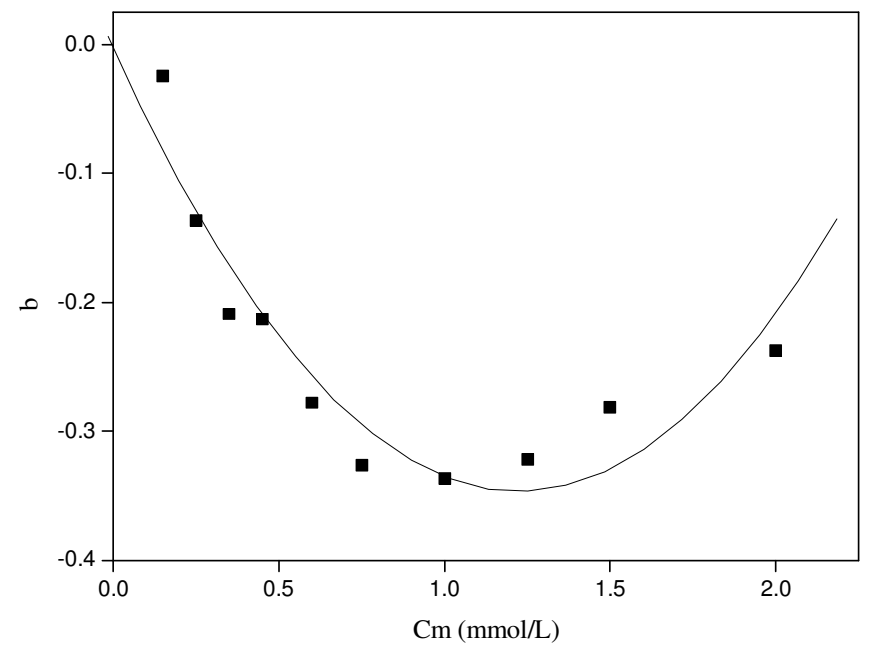

were negative, it mean that an increase in the hydrogen bond basicity decreases the overall adsorption of the molecule. In all the concentration investigated most of the values of $\mathrm{s}$ were positive, it mean that an increase in the solute dipolarity/ polarizability increases the overall adsorption of the molecule. In view of value range of coefficients, the hydrogen bond basicity $\left(\Sigma \beta_{2}{ }^{\mathrm{H}}\right)$ and solute dipolarity/polarizability $\left(\pi^{\mathrm{H}}\right)$ generally play the largest role in determining the adsorption of solutes in all studies.

TABLE-5

CONSTANTS FOR THE ADSORPTION EFFECTS OF SINGLE COMPOUND USING SOLVATION PARAMETER MODEL

\begin{tabular}{cccccc}
\hline \multirow{2}{*}{$\begin{array}{c}\mathrm{Cm} \\
(\mathrm{mmol} / \mathrm{L})\end{array}$} & $\mathrm{b}$ & $\mathrm{a}$ & $\mathrm{s}$ & $\mathrm{m}$ & $\mathrm{c}$ \\
\cline { 2 - 6 } & -0.0246 & 0.0000 & -0.0123 & 0.0000 & -1.0385 \\
0.15 & -0.1365 & 0.0000 & 0.0464 & 0.0000 & -0.7564 \\
0.25 & -0.2088 & 0.0000 & 0.0774 & 0.0000 & -0.5517 \\
0.35 & -0.2132 & 0.0000 & -0.0303 & 0.0000 & -0.1455 \\
0.45 & -0.2775 & 0.0000 & 0.0347 & 0.0000 & -0.0751 \\
0.60 & -0.3260 & 0.0000 & 0.0401 & 0.0000 & 0.0998 \\
0.75 & -0.3363 & 0.0000 & 0.0269 & 0.0000 & 0.2719 \\
1.00 & -0.3216 & 0.0000 & 0.0126 & 0.0000 & 0.3798 \\
1.25 & -0.2813 & 0.0000 & 0.0188 & 0.0000 & 0.3727 \\
1.50 & -0.2375 & 0.0000 & 0.0238 & 0.0000 & 0.4017 \\
2.00 & & & & & \\
\hline
\end{tabular}

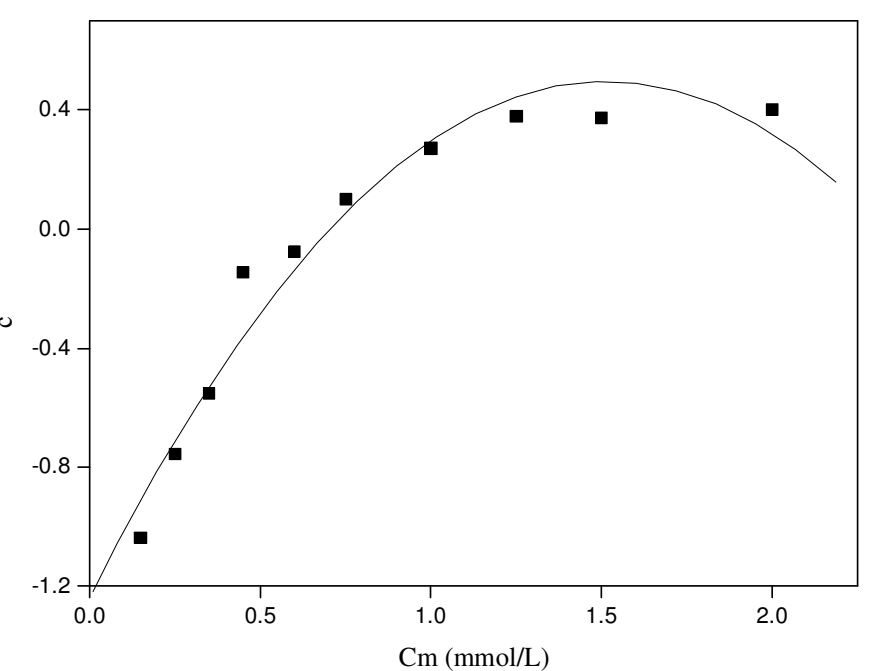

Fig. 2. LSER coefficients as a function of concentration of single compound 

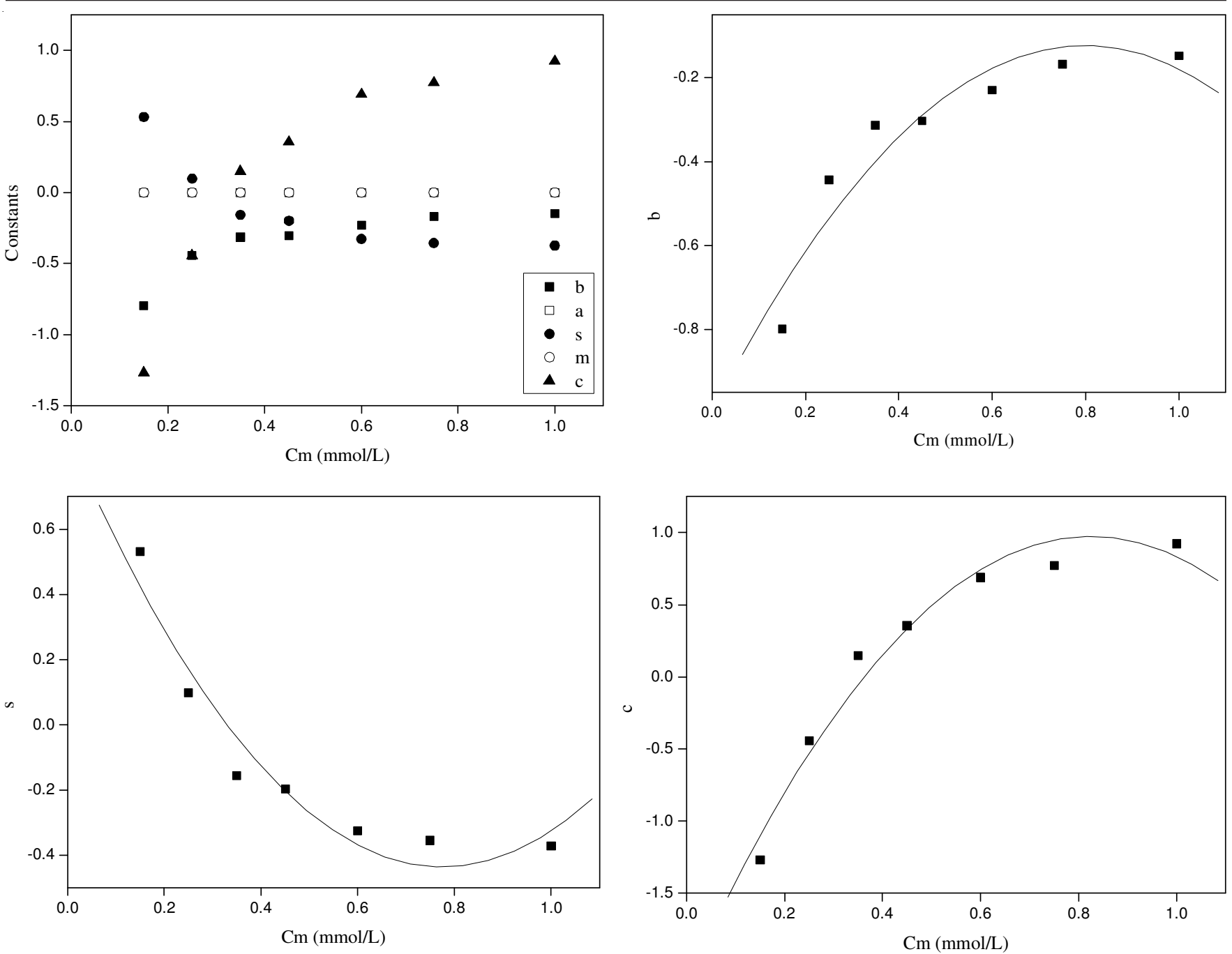

Fig. 3. LSER coefficients as a function of concentrations of mixture compounds

TABLE-6

CONSTANTS FOR THE ADSORPTION EFFECTS OF MIXTURE COMPOUNDS USING SOLVATION PARAMETER MODEL

\begin{tabular}{cccccc}
\hline \multirow{2}{*}{$\begin{array}{c}\mathrm{mm} \\
\mathrm{mmol} / \mathrm{L})\end{array}$} & $\mathrm{b}$ & $\mathrm{a}$ & $\mathrm{s}$ & $\mathrm{m}$ & $\mathrm{c}$ \\
\cline { 2 - 6 } & -0.7993 & 0.0000 & 0.5306 & 0.0000 & -1.2696 \\
0.15 & -0.4432 & 0.0000 & 0.0982 & 0.0000 & -0.4443 \\
0.25 & -0.3138 & 0.0000 & -0.1574 & 0.0000 & 0.1482 \\
0.35 & -0.3032 & 0.0000 & -0.1979 & 0.0000 & 0.3559 \\
0.45 & -0.2296 & 0.0000 & -0.3263 & 0.0000 & 0.6905 \\
0.60 & -0.1677 & 0.0000 & -0.3552 & 0.0000 & 0.7723 \\
0.75 & -0.1481 & 0.0000 & -0.3724 & 0.0000 & 0.9243 \\
1.00 & & & & &
\end{tabular}

The coefficient ' $b$ ' is the most important factor in the LSER solvation parameter model used in this study. A comparison of the coefficients for each concentration of solute reveals that $\mathrm{b}$ have the largest absolute values among all coefficients for all concentrations presented here. The $b$ coefficient is proportional to the difference in the hydrogen bond donating ability of the concentration of solute. A larger b coefficient reflects that more solutes partition out of the organic solutions environment of the solute and the average solute environment appears to be less polar and higher hydrogen bond donating ability strength of the adsorption concentration. The difference in dipolarity/polarizability is represented by the coefficient s. A positive sign for this coefficient indicates that the solutes experience a microenvironment that has larger dipolar/ polarizable characteristics than the other sorbents. As the concentration of solutions increasing, the trend of $\mathrm{s}$ was irregular arrange from -0.04 to 0.08 .

As shown in Fig. 2, the values of all of the 2 coefficients (b and c) changed complicatedly as the concentrations of three compounds changing. In Fig. 3 , the values of all of the 3 coefficients (b, s and c) changed complicatedly as the concentrations of three compounds changing. It mean that the hydrogen bond basicity and solute dipolarity/polarizability changed with adsorption effects changing. The constants of LSER model were also predicted using Logarithmic and Polynomial equations (Table-7). Calculated $\log$ Cs values of the three polyphenols compounds were computed for adsorption concentrations using Eqn. 1. And the relationship between calculated (Cal.) and experimental (Exp.) $\log$ Cs were showed in Fig. 4. The solvation parameter model is found to provide statistically and chemically results. The correlation between experimental (Exp.) and calculated (Cal.) log Cs (Concentrations from 0.15 to $2 \mathrm{mmol} / \mathrm{L}$ demonstrated in Fig. 4 . It showed that LSERs are able to approximately reproduce the experimental $\log \mathrm{Cs}$ values for the solutes studied in the 

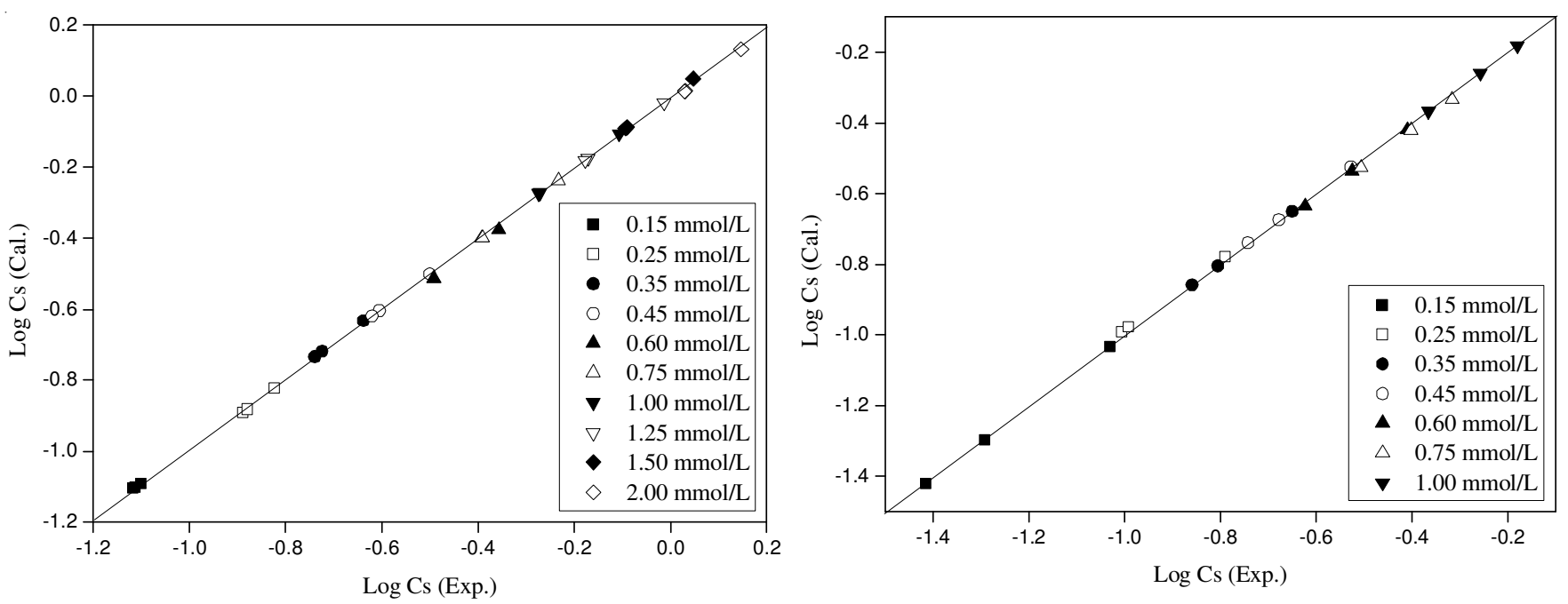

Fig. 4. Correlation between experimental (Exp.) and calculated (Cal.) log Cs. (a) Single compounds; (b) Mixture compounds

\begin{tabular}{|c|c|c|}
\hline \multicolumn{3}{|c|}{$\begin{array}{c}\text { TABLE-7 } \\
\text { EQUATIONS FOR CALCULATE THE LSER CONSTANTS } \\
\text { OF SINGLE AND MIXTURE COMPOUNDS }\end{array}$} \\
\hline & Equations & $\mathrm{R}^{2}$ \\
\hline \multirow{2}{*}{$\begin{array}{c}\text { Single } \\
\text { compound }\end{array}$} & $\mathrm{b}=0.2290 \times \mathrm{Cm}^{2}-0.5600 \times \mathrm{Cm}-0.0030$ & 0.8840 \\
\hline & $\mathrm{c}=-0.7560 \times \mathrm{Cm}^{2}-2.2920 \times \mathrm{Cm}-1.2390$ & 0.9590 \\
\hline \multirow{6}{*}{$\begin{array}{c}\text { Mixture } \\
\text { Compounds }\end{array}$} & $\mathrm{b}=0.3210 \times \ln (\mathrm{Cm})-0.0700$ & 0.8840 \\
\hline & $\mathrm{b}=-1.3710 \times \mathrm{Cm}^{2}+2.1880 \times \mathrm{Cm}-0.9960$ & 0.8960 \\
\hline & $\mathrm{s}=-0.4700 \times \ln (\mathrm{Cm})-0.5090$ & 0.8890 \\
\hline & $\mathrm{s}=2.1980 \times \mathrm{Cm}^{2}-3.4110 \times \mathrm{Cm}+0.8860$ & 0.9350 \\
\hline & $\mathrm{c}=1.1650 \times \ln (\mathrm{Cm})+1.1550$ & 0.9500 \\
\hline & $\mathrm{c}=-4.5880 \times \mathrm{Cm}^{2}+7.5220 \times \mathrm{Cm}-2.1270$ & 0.9670 \\
\hline
\end{tabular}

different concentrations whether single or mixture compounds of quercetin, catechin and epicatechin on quercetin-molecular imprinted polymer.

\section{Conclusion}

Three polyphenols applied as solutes in the organic solutions on quercetin-molecular imprinted polymer. The quercetin-imprinted polymer shows extraordinarily higher adsorption ability for quercetin than for the two catechin compounds that were also assessed. The LSER model, i.e., the solvation parameter model, was successfully applied to investigate the effect of the concentrations on adsorption of quercetin, catechin and epicatechin on quercetin-molecular imprinted polymer. The results obtained from the solvation parameter model provide comparable information, for example, coefficient $b$ and coefficient s play the most important role in adsorption behavior in organic conditions. It is worth noting that, using the obtained LSER models, it is possible to predict adsorption concentrations with high correlation coefficients $\left(r^{2}>0.99\right)$. It is evident from the results of the LSER model that the hydrogen bond basicity and solute dipolarity/polarizability have dominant effects role on the solute and sorbents interaction. This model is a helpful tool to understand the solute-organic compound interactions and evaluate the adsorption characteristic of molecular imprinted polymer.

\section{ACKNOWLEDGEMENTS}

This research was supported by the Science and Technology Commission of Shanghai Municipality (12290502200), Natural Science Foundation of China (51269032), Shanghai University Knowledge Service Platform and Shanghai Ocean University Aquatic Animal Breeding Center (ZFI206) and Agricultural Science \& Technology Independent Innovation Fund of Jiangsu Province (SCX[11]3033), China.

\section{REFERENCES}

1. W. Chen, F. Liu, X. Zhang, K.A. Li and S. Tong, Talanta, 55, 29 (2001).

2. N. Zheng, Y.Z. Li, W.B. Chang, Z.M. Wang and T.J. Li, Anal. Chim. Acta, 452, 277 (2002).

3. Y. Jin and K.H. Row, Bull. Korean Chem. Soc., 28, 276 (2007).

4. Y. Jin, Y.H. Xuan, Y.S. Jin and K.H. Row, J. Liq. Chromatogr. Rel. Technol., 34, 1604 (2011).

5. Y. Jin and K.H. Row, Chem. Res. Chin. Univ., 23, 412 (2007).

6. Y. Jin and K.H. Row, Korean J. Chem. Eng., 22, 264 (2005).

7. Y. Jin, C.C. Liu, S.H. Sun and K.J. Lee, Asian J. Chem., 24, 2461 (2012).

8. F. Gritti and G. Guiochon, J. Chromatogr. A, 1155, 85 (2007).

9. Y. Wang, M. Tian and K.H. Row, J. Liq. Chromatogr. Rel. Technol., 33, 202 (2009).

10. Y. Wang, D. Han, T. Tian and K.H. Row, Korean J. Chem. Eng., 26, 812 (2009).

11. M.J. Kamlet, R.M. Doherty, M.H. Abraham, Y. Marcus and R.W. Taft, J. Phys. Chem., 92, 5244 (1988).

12. M.J. Kamlet, R.M. Doherty, P.W. Carr, D. Mackay, M.H. Abraham and R.W. Taft, Environ. Sci. Technol., 22, 503 (1988).

13. T. Wang, X. Wang Jr. and R.L. Smith Jr., J. Supercrit. Fluids, 35, 18 (2005).

14. M. Tian, S. Li and K.H. Row, Korean J. Chem. Eng., 28, 357 (2011).

15. K.H. Row and Y. Jin, Bioresour. Technol., 97, 790 (2006).

16. Y. Jin and K.H. Row, J. Liq. Chromatogr. Rel. Technol., 30, 335 (2007).

17. Y. Jin, C.H. Jin and K. Ho Row, Biotechnol. J., 1, 209 (2006).

18. Y. Chen, M. Kele, I. Quinones, B. Sellergren and G. Guiochon, J. Chromatogr. A, 927, 1 (2001).

19. A. Zurutuza, S. Bayoudh, P.A.G. Cormack, L. Dambies, J. Deere, R. Bischoff and D.C. Sherrington, Anal. Chim. Acta, 542, 14 (2005).

20. P. Jandera, P. Cesla, T. Hajek, G. Vohralik, K. Vynuchalova and J. Fischer, J. Chromatogr. A, 1189, 207 (2008). 